\title{
LA PERCEPCIÓN COMO INTERPRETACIÓN ${ }^{1}$
}

\author{
Javier San Martín \\ UNED. Madrid
}

Ante todo quiero manifestar mi agradecimiento y felicitación al profesor Pedro Alves por esta iniciativa, que, posiblemente, no es más que un comienzo de una relación que no tiene otra salida que profundizarse en el futuro, quedando, en todo caso, obligados, nosotros, los compañeros españoles, a replicar esta iniciativa en España. Por supuesto, quiero agradecer también a Jesús Díaz por el trabajo preciso con ha configurado el grupo de participantes.

Dicho esto, para no consumir más tiempo en prolegómenos, me gustaría centrar el tema de mi ponencia en sus justos términos.

\section{Centrando el tema}

Ante todo quiero subrayar la importancia que en la fenomenología en general, y en la husserliana en particular, tiene una correcta comprensión de la percepción. Parto de mi convencimiento de que en la presentación de las Ideas I, en 1913, hay una cierta oscuridad o ambigüedad del tema que ha perdurado en la comprensión de la fenomenología, no sólo de la husserliana, sino de toda fenomenología, si exceptuamos la de Merleau-Ponty, cuyo objetivo fundamental muy bien podría ser formulado como un rescate de la teoría de la percepción de los problemas en los que se ve inmersa por el lugar en que es tratada en las Ideas I.

Como este punto tiene su importancia, voy a dedicarle unas líneas. El problema viene del lugar en que es tratada la percepción, después de la sección segunda, en la que se practica una epojé de la tesis de la actitud natural en que

1 Este ensayo se ha realizado con la ayuda del proyecto de investigación "La filosofia ante los retos de un mundo plural", del Ministerio de Educación y Ciencia 2005-2007, HUM2004$-03533 /$ FISO. 
se pone el mundo. Por tanto, la descripción fenomenológica de la percepción aparece como neutralizada, eso significa comprender la percepción en una especie de limbo, que sería el espacio en el que parece desenvolverse el fenomenólogo. En efecto, la percepción es analizada como un acto ponente de realidad, atravesada por una doxa, como carácter tético del acto perceptivo, cuyo correlato es el ser. Ahora bien, como estamos en una actitud fenomenológica, el descriptor de esos actos toma la percepción en una actitud del como-si.

En segundo lugar, hay en las Ideas, como el propio Husserl confesará en el último texto publicado al respecto en Hua XXIX, un olvido del carácter histórico del mundo, por tanto, del carácter concreto de la percepción, que no es percepción en general, sino percepción de esta cosa en este mundo, y en esta finalidad concreta o para esta acción determinada, todo lo cual son elementos culturales que la determinan y diferencian en cada caso hasta el punto de hacer perceptivas realidades diferentes en cada cultura o, incluso, dentro de cada cultura, según los diversos mundos particulares que en ella pueden darse, determinados por la profesión, posición, edad o género. Lo que percibe por ejemplo un torero en el toro puede tener poco que ver con lo que percibe un carnicero o un artista. Lo que percibe en una mujer otra mujer puede ser radicalmente diferente de lo que percibe un hombre, y lo que percibe éste puede ser muy distinto de lo que percibe otro según sea su compromiso machista o feminista. La "gran diferencia" sexual se puede convertir en la "pequeña diferencia", y las consecuencias de una y otra ser profundamente distintas en multitud de planos. Todos estos aspectos estarían implicados en la crítica heideggeriana, sea pertinente o no, a la teoría husserliana de la percepción en las Ideas.

Tan es así el tema en la problemática señalada que la teoría del nóema de Føllesdall ha determinado toda la corriente promovida por Dreyfus de interpretación de la fenomenología husserliana como una psicología cognitiva, de carácter representacionista, en la que se analiza la experiencia como configuradora de una representación del mundo, perfectamente adaptable, en una tarea científica rigurosa que se lleva a cabo en la ciencia cognitiva, a la nueva realidad ontológica promovida por la ciencia de la computación. Esta secuencia, nada desdeñable, de interpretación de la fenomenología en la contemporaneidad más actual, hace que la teoría de la percepción de la fenomenología se convierta en el punto central de evaluación del lugar filosófico que ocupa la fenomenología.

No quiero dejar de aludir, en este momento en el que salimos de la celebración del 50 Aniversario de la muerte de Ortega, a su perspicacia, dentro de los límites de su juventud y de los materiales de que disponía, al tomar conciencia, seguramente aporética, de los diversos planos, opuestos o complementarios - ahí estaría la discusión - de lo que muy pronto, ya en 1914, en el "Ensayo de estética a manera de prólogo" tematizó como la diferencia entre lo 
ejecutivo y lo virtual. Efectivamente, ése es el tema básico para comprender la percepción: o en ella nos movemos en un terreno ejecutivo, o en un terreno virtual. El ejemplo mismo que pone Ortega, el sol, nos da pie a hablar de una oscilación aporética suya en ese momento, del sol. Porque, para Ortega, el sol es para sí mismo ejecutivo, ejecuta su ser, es decir, es combustión, se quema, pero, según el texto de Ortega al que me refiero, la imagen del sol que se da en mi conocimiento no quema, no es ejecutiva, es virtual. Lo aporético consistirá en esa concepción del conocimiento como algo no ejecutivo, cuando, a partir de su madurez, la toma de contacto con la realidad será en el modo de contar con las cosas, modo en el que las cosas, como yo que interactúo con ellas, estamos en una relación ejecutiva. Por ejemplo, el sol con el que yo cuento es ejecutivo, podríamos decir que, si lo miro, quema e ilumina y por eso cuento con él.

Todo esto es una aproximación a la amplia problemática presente en el tema de la percepción. Ahora bien, si yo lo he traído a esta Jornadas Ibéricas de Fenomenología es, primero, porque este tema subyace a cualquier discusión en el terreno de la pluralidad cultural; $y$, segundo porque vuelve en el magnífico libro de Lester Embree Análisis reflexivo, ${ }^{2}$ de un modo en el que yo percibo cierta problematicidad, que no trato en la presentación que del libro hice en la reciente edición electrónica de Investigaciones fenomenológicas, pero sobre la cual discutí ampliamente en correspondencia con el propio Lester Embree. Dada la indudable repercusión que ha de corresponder al libro de L. Embree, me ha parecido oportuno exponer los puntos fundamentales de la teoría de la percepción tal como yo la entiendo, aunque pueda mantener alguna discrepancia con la presentación de Lester Embree.

Quiero empezar dándole la razón a su deseo de hacer una fenomenología descriptiva y no erudición, pues ya es hora de que nos esforcemos por ir a las cosas mismas, aunque me gustaría apuntarme a la indicación de Roberto Walton, ${ }^{3}$ de que cuando comentamos textos procuramos mirar las cosas y, así, como fenomenólogos no nos interesan los textos en sí, sino en la medida en que con ellos tratamos de leer las cosas mismas. En este sentido creo, siguiendo a Lester Embree, que hay que rechazar una fenomenología meramente erudita, mas también que debemos confesar que por lo general todos o casi todos procuramos ir a las cosas mismas con los textos, entre los cuales está, ahora, el propio libro de Lester Embree. Con su teoría pasa lo mismo que les pasó a las vanguardias artísticas, que luchan contra el concepto usual de arte, para eliminarle todo compromiso convencional, ya que, en el momento

2 Lester Embree, Analisis reflexivo Una primera introducción a la investigación fenomenológica. Reflective Analysis. A First Introduction into Phenomenological Investigation. Edición bilingüe, inglés/castellano. Trad. al castellano de Luis Rabanaque. Red Utopía, Jitanjáfora, Morelia, 2003.

3 En conversación privada y que Roberto Walton ha plasmado en la reseña que pronto saldrá en Escritos de Filosofia. 
en que la obra de vanguardia se convierte en obra de arte, entra en el circuito económico museístico del arte que quería superar. El libro de L. Embree se convierte en un texto con el cual sus lectores e intérpretes nos vamos a referir a las cosas. Para ello, aquí, miraremos a Husserl y a Lester Embree, y con esa mirada trataremos de ponderar las cosas mismas para ver con qué descripción nos quedamos, en caso de que hubiéramos notado alguna diferencia.

\section{La teoría husserliana de la percepción en Ideas I}

Las Ideas I pasan por ser la presentación pública del método fenomenológico a la altura de los desarrollos de 1913. Hay intérpretes que opinan, sin embargo, que ese libro no es como tal un libro, sino una recopilación de varios textos que tendrían escasa unidad entre sí. Sea la interpretación sobre la redacción de las Ideas $I$ lo que fuere, en él se da una teoría de la percepción, que me gustaría delinear, aunque, obviamente, sólo con gruesos trazos, como no puede ser de otro modo en estas escasas líneas, de cara a subrayar el punto que me interesa, y más que otra cosa desde la intención de suscitar el debate.

Empezaré relacionando esa teoría con un problema que motivará la, desde un punto de vista, razonable crítica heideggeriana y con un tema que no dejaría de suscitar motivos de reflexión en discípulos cercanos a Husserl como Gurwitsch o Dorion Cairns. Esta mención no es para centrarme en ella sino sólo para aludir a un problema que, aunque no interfiere en la tesis que defenderé, creo conveniente citar. Me refiero a la cuestión de hasta qué punto la teoría de la percepción de Husserl en la Ideas no toma una percepción "reducida" bien a lo que llamará Husserl en Ideas II actitud naturalista, una actitud propia del científico, en la que se han eliminado los predicados culturales que provienen de los otros; bien resultado de lo que Husserl llamará "reducción a la esfera de pertenencia", tema muy posterior en esos términos pero que muy pronto aparecerá con el nombre de "Gedankenexperiment". En efecto, cabe preguntarse por el tipo de acto llamado percepción al que Husserl aplica sus análisis en Ideas $I$, y lo que parece claro es que esa percepción no es la percepción ordinaria que está imbricada en la acción cotidiana en el mundo cultural sino una percepción en la que se han eliminado los elementos que según Ideas II son los elementos de la actitud personalista, por tanto los elementos histórico culturales.

Ese es el primer rasgo básico que el propio Husserl anotará más adelante, el mundo tomado en consideración en las Ideas, y que es el mundo que ha pasado como el mundo del que, al menos en esa obra, habla la fenomenología no es el mundo histórico concreto atravesado de una finalidad instrumental, en el que las percepciones concretas son de cosas encajadas en sus series de remisiones culturales, sino un mundo constituido de dos niveles, por un lado, la presencia misma del mundo, como horizonte dimensional en el que todo apa- 
rece y, por otro, como las cosas presentes en ese mundo a las que yo atiendo de un modo $u$ otro. Para llegar a ese mundo he tenido que traspasar o superar mi primer compromiso con el mundo, que es un compromiso con mi mundo histórico concreto en el que yo vivo.

Ahora bien, las Ideas empiezan con una sección que muchas veces no deja de desorientar, pues en ella lo que se da es una descripción del modo cómo es el mundo real, el mundo en el que vivimos, que no es un mundo sin más sino un mundo atravesado por una estructura de significados. Yo suelo decir que al menos uno de los sentidos de esa sección no es otro que recordarnos que el mundo es el conjunto de los hechos clasificados, de manera que, más que los hechos, en el mundo resalta la clasificación de los hechos, y que de entrada vivimos en esa clasificación, por tanto en estructuras esenciales, porque de eso se trata, de que vivimos en una clasificación, en una distribución en clases, pues todo hecho aparece enmarcado en su respectiva clase o esencia. Obviamente, la matriz fundamental de las clases no es otra que el lenguaje.

Después de esa sección, viene la de la reducción y epojé, en la que se trata de acceder a la región de la conciencia pura, una conciencia para llegar a la cual he puesto la tesis de la actitud natural entre paréntesis, por tanto, dejo de dar "crédito" a la actitud natural en la que esa clasificación del mundo es clasificación de un mundo real. Y sólo entonces, ya en la sección tercera, iniciará Husserl la descripción de los actos de esa conciencia "pura".

Naturalmente que esa sección segunda ha hecho correr mucha tinta, no sólo a los intérpretes, sino también al mismo Husserl, que dio vueltas y revueltas a lo que él quería decir exactamente en esas páginas. Entre los mayores problemas el principal está en el estatus de esa conciencia pura en su relación con el mundo real. Desde el texto de Ideas, ese aspecto es un tanto problemático, y ése es el tema que más horas de reflexión llevará a Husserl hasta tener clara la distinción entre el yo que hace la epojé, es decir, el yo fenomenólogo que reflexiona y no da crédito a la tesis de la actitud natural, y el yo trascendental que de siempre pone un mundo. Pero no es un tema que ahora nos preocupe porque el no dar "crédito" - en un sentido diríamos "economista" de la palabra, quiero decir, adoptando la actitud de un analista que inspecciona los "créditos" para analizar, por ejemplo, la morosidad, por tanto, sin hacer uso de ellos, con lo que opera con ellos en un plano teórico- no interfiere en la eficacia de la actitud natural. Lo que me interesa es tomar conciencia de que el mundo que me queda es el mismo que antes sólo que ahora sin la fuerza "tética" que parece tener en la actitud natural.

Una vez superada esa primera fase, el análisis husserliano se va a centrar en los actos de la conciencia pura. Y aquí tenemos una primera dificultad, que él mismo asume, al avisarnos que se centra en la intencionalidad de acto, dejando de lado toda las capas anteriores de la intencionalidad que no son una intencionalidad de acto. Porque la pregunta primera es si la "percepción" es un acto. Evidentemente, yo percibo cosas, aunque sólo percibo cosas porque 
de entrada ya estoy en un mundo. No nos preocupemos ahora si ese mundo es el mundo histórico-cultural, o un mundo previo y sustrato de ese mundo. Husserl siempre analiza la percepción como un acto, pues ése es el nivel de las Ideas. Pero ese análisis le va a llevar al tema fundamental, de que la percepción como un acto vive de la percepción como "presencia del mundo", y éste es el tema clave.

$\mathrm{El}$ análisis de la percepción parte, primero, de una confesión de que se dejan las capas profundas ["die dunklen Tiefen", III, 208, lín. 3; § 85) de la temporalidad, en las que se constituye todo elemento. Segundo, de la diferencia entre lo que llama "contenidos primarios", que también denomina "materia (hyle) sensual" y lo que será la "forma" (morphe) intencional". En la materia están los contenidos sensuales, entre los cuales cita, en una postura que se puede conceptuar de sensualista, "Empfindungsinhalte" (lín. 13 s.) como, por ejemplo, datos de color (Farbendaten), diferenciados de los colores presentados a través de esos datos (de los "erscheinenden dinglichen Momenten, Farbigkeit" lín. 15), cuando fenomenológica-mente es obvio que de los colores no hay ningún dato sensual, el color no está en mi cuerpo sino en las cosas coloreadas. Pero independientemente de esto, que yo considero desliz fenomenológico, hay funciones intencionales que me hacen ir de una parte del objeto a otra, intencionándolo de un modo u otro.

Una vez establecida esa distinción, en el capítulo siguiente, el III, va a entrar Husserl en el tema más importante de su consideración sobre la percepción, el hecho de que la percepción consta, como toda vivencia, de elementos reales (reell) noéticos, y de correlatos intencionales, o "contenido noemático", o "de modo resumido - kurzweg-Nóema" (p. 219, lín. 20). En la percepción el nóema es "lo percibido en cuanto tal" (als solches). Partiendo de ahí, introduce una distinción que va a ser clave en la fenomenología, y especialmente para nosotros, los españoles, por el uso que Ortega va a hacer de ella, la que se da entre el sentido que pertenece esencialmente a la percepción tal como la estamos describiendo, como algo "reducido" ("In der reduzierten Wahrnehmung", p. 221, lín. 32), y las cosas en sí mismas. Husserl lo va a expresar plásticamente de una manera que perdurará, además, con el mismo ejemplo a lo largo de toda su obra, hasta la Krisis (p. 245), que el árbol como cosa natural se quema, mientras que el sentido de árbol que pertenece de modo inherente a la percepción, no se quema.

En esa frase no deja de haber una ambigüedad, porque, por una parte, se establece una diferencia básica entre dos niveles de realidad, la realidad que se compone con otras realidades, y en este caso, que se queman, y el otro nivel, el del sentido, al que no se puede aplicar leyes naturales. La ambigüedad consiste en que, en este lugar, la diferencia entre lo real natural que se quema y el sentido que no se quema parece ser resultado de la reducción, ella es la que descubre ese nivel del sentido, lo percibido en cuanto tal, pero Husserl tiene claro, por otro lado, que el sentido en cuanto tal pertenece a la percepción porque 
dice con toda claridad: "El sentido perceptivo es inherente, como se comprende de suyo, también a la percepción no reducida fenomenológicamente", lo que significa que la percepción, como toda vivencia, tiene un sentido, cuyo modo de ser es, lo voy a decir con palabras que utilizará Ortega profusamente en ese momento para referirse a ese sentido, una realidad virtual, que es lo que constituye el objeto intencional de cada vivencia, y en el parágrafo siguiente dice que el tener cada percepción, como cada vivencia, su objeto intencional es el "das Grundstück der Intentionalität", "el meollo de la intencionalidad", como traduce José Gaos (Ideas, p. 117).

El parágrafo siguiente, el $\S 90$, es decisivo, primero para aclarar la diferencia, que aún no será eficaz, entre el objeto real y el objeto intencional. Segundo, y es lo más importante, para despejar una duda, el objeto intencional no es una imagen o signo a través del cual lleguemos al objeto real. Tercero, para aclarar que ese sentido es una especie de núcleo, "Kernschicht", que pertenece a toda vivencia y que en cada una de ellas se complementará con "otros momentos", "weitere Momente" (223, lín. 15), que serán los respectivos "momentos de sentido". Cuarto, nos aclarará el sentido de la reducción, que aquí es tomar la percepción como se da, por tanto para hacer afirmaciones, no sobre el objeto real, sino sobre la percepción y su objeto tal como se da. Y quinto, y es lo más importante, aunque lo diga en negativo: la situación de reducción en que estamos "no impide juicio alguno que diga que la percepción es conciencia de una realidad" (p. 226; 220), ni describir esta "realidad en cuanto tal", es decir, como se da.

Precisamente, lo interesante va a estar en esta descripción, que en lo que a nosotros nos interesa empezaría justo aquí, porque deben compaginar los diversos elementos que han ido saliendo hasta ahora. Y lo primero es una constatación de Husserl de acuerdo a lo que ha dicho, a saber, que el sentido noemático tiene un núcleo central, el sentido objetivo en torno al cual se agrupan otros caracteres; ese núcleo objetivo correlato es idéntico en diversas vivencias, por ejemplo, un árbol con flores puede ser el mismo en una percepción, en un recuerdo, en un deseo, en una pregunta. Y con esto ya pasa a analizar la percepción en concreto, al menos como un ejemplo, de acuerdo a sus estructuras reales, es decir, noéticas, y a las noemáticas. En cuanto, a las noéticas, se trata de saber qué pertenece a la percepción, por ejemplo, del árbol. Y lo primero, comenta, están los elementos materiales y los noéticos (p. 242, lín. $35 \mathrm{~s}$.). Y aquí repite de nuevo el mismo error que en mi opinión se había ya anunciado, porque el color percibido no pertenece a la percepción pero sí "die Empfindungsfarbe" (243, lín. 7), el momento hilético de la vivencia en que se escorza [abschattet] el color objetivo noemático. En realidad a la hora de hacer concreto ese momento hilético real menciona Husserl "la posición de los ojos, las orientaciones relativas", llevando la mirada, unas veces al tronco, otras a las hojas, otras a las ramas, flores, o nos acercamos o alejamos. Obviamente, en todo ello no encontramos fenomenológicamente nada de color, es decir, 
alguna sensación visual sino sólo elementos táctiles, es que en realidad todo color es noemático. Sin embargo, no nos preocupa este posible problema porque no afecta al punto que será decisivo. Esos elementos hiléticos, sean los que fueren, aparecen "animados" (beseelt) por los elementos noéticos como elementos reales de la vivencia. Y termina que al campo fenomenológico que queda después de la reducción pertenece "el modo cómo lo real mismo es consciente en la conciencia” (245, lín. 17), y eso en la percepción, el modo en que la conciencia es consciente de cosas reales.

Al estudio del nóema en la percepción está dedicado el $\S 99$, pues eso idéntico en varias vivencias se da en cada una de modo distinto, por ejemplo, en la percepción "originariamente" ("originär"), y por ejemplo, en el recuerdo, en el modo del recuerdo. S añade Husserl una precisión fundamental para nosotros, estos caracteres que pertenecen al sentido noemático no pertenecen a una serie, (250, lín. 29) - y subraya la palabra 'una'-, porque otros modos remiten a la percepción. No se suele tomar en consideración este dato clave de Husserl, que es el que va a marcar toda su fenomenología tanto en general porque en esa constatación fenomenológica se decide el tono de su filosofía, como la fenomenología de percepción, y esto no en las últimas obras sino desde el principio, porque, además una fenomenología que se atiene a los datos no encuentra esa presunta "serie" en la que las vivencias serían etiquetas que se refieren a un "sentido objetivo" de diversos modos, sino que en ellas hay un rango clave, y ese rango viene determinado por el modo en que se da lo originario, es decir, por la percepción.

Después de analizar una serie de estructuras de relaciones, vuelve a la percepción para precisar la constitución interna de la misma, y señala en primer término que al carácter dóxico o de creencia, como percatación (Gewahrung) (256, lín. 12) de las representaciones intuitivas, es decir, de la percepción, recuerdo o expectativa, corresponde como carácter noemático el ser real. Por eso todos esos actos son "actos ponentes", ponentes de ser, por tanto actos téticos. Esa creencia, que aparece en la percepción como "certeza de creencia" (Glaubensgewisstheit) se puede modificar, pero en la serie de modificaciones de la creencia, la certeza de la creencia original "desempeña el papel de la no modificada o, como habríamos de decir aquí, de la "no-modalizada forma original del modo de creencia" (257 s.), y correlativamente, el modo de ser real puesto en la percepción, desempeña el modo originario de ser, "die Urform aller Seinmodalitäten". Y esto ya se aplica a la totalidad del nóema, al nóema en cuanto sentido objetivo y en cuanto a los caracteres de ser.

Pero no terminaremos de completar la exposición husserliana sin tomar en consideración su fenomenología de la razón, es decir, la sección IV de las Ideas I, que en lo que nos interesa tiene dos partes, una primera preparatoria, en la que, como introducción de la fenomenología de la razón en sentido estricto, se dilucidan algunos de los problemas más importantes de la problemá- 
tica del nóema, para, en la segunda parte, apuntar las bases claves de una fenomenología de la razón.

Ahora se trata de estudiar aquel núcleo noemático, hacerle justicia a eso noemático, y a través de la dilucidación de las diversas frases al respecto llega Husserl a la conclusión de que en el núcleo hay que distinguir el contenido, que hace de soporte de la intención, y el objeto al que va la intención, este es el "qué" de la intención, el "was", y el otro, el sentido noemático, que es lo que conseguimos al hacer una descripción del contenido "exactamente tal como está mentado". Esta descripción debe expresarse en conceptos de carácter formal y material (ver, p. 319, lín. 35 ss; $\S 130$ ). Quiero subrayar este aspecto, porque no debe pasar desapercibido el tema de que el contenido noemático es describible, es decir, que puede ser transferido a predicados, que "determinan el contenido del núcleo del nóema del objeto del que se trata" (p. 320, lín. 3) con lo que ya tenemos una aproximación a las palabras, conceptos o ideas. Luego tendremos que volver al tema.

Pero aún quedan dos pasos, uno el hecho de que ese contenido es siempre contenido de algo al que sin embargo no podemos dar más determinación que el ser "lo idéntico", lo "determinable de sus posibles predicados o pura X", con abstracción de los mismos, el punto de unidad del que somos conscientes cuando recuerdo una cosa que es la misma por ejemplo que estoy viendo ahora. No son los predicados o determinaciones que lo identifican, sino lo que une todas esas determinaciones, "el centro necesario, el punto de unidad, la pura x determinable” (p. 322, lín. 22; § 131). En el § siguiente amplía las explicaciones que ya diera en los $\S \S 103$ y 104, que, a su vez, se remiten a los que ahora estoy comentando. Pues los caracteres posicionales, por tanto de ser, en el caso de la percepción, de ser real, que pertenecen al nóema, y que se dan, en la unidad de sentido y carácter tético (p. 324, lín. 11), como correlato del carácter noético de la creencia originaria, ahora se asumen como una proposición, como un Satz, de manera que en la percepción tenemos una proposición de un miembro. No hay que asustarse con el término "proposición", pues sólo es el abstracto de proponer, y ese es el carácter de la percepción, que en ella hay la propuesta de la realidad de una cosa. Por eso al nóema de una percepción pertenece el implicar la tesis de una cosa, el poner una cosa, y por tanto ese nóema, como unidad de sentido y caracteres téticos, es un Satz, una propuesta.

Una vez llegados a este punto, ya acomete Husserl la auténtica fenomenología de la razón, que para mí es uno de los capítulos más importantes de todos los escritos por Husserl. Se parte de la pretensión de las percepciones de poner un objeto real, cuando acaba de ver que el objeto real tiene que estar "representado" [vertreten] (p. 329, lín. 17) en la conciencia "por todos los sentidos y proposiciones variablemente llenas en las cuales es el correlato de posibles vivencias intencionales", pues bien, eso induce a plantear el problema de si ese objeto del que tenemos conciencia de que es el mismo, es real- 
mente el mismo. En el caso del objeto real, la pregunta es si es ese mismo el objeto real.

Ahora bien, en el caso de la percepción (o de otro tipo de vivencias en las que hay una captación evidente, como, por ejemplo, en proposiciones matemáticas) hay una vivencia de la legitimidad de la vivencia para poner su objeto como real. Hay una "Rechtsprechung der Vernunft", hay un pronunciamiento de legitimidad de la razón. Quizás al traducir Vernunft como razón, perdemos el sentido de esa frase, porque razón en las lenguas románicas es una denominación de una potencia, mientras que en alemán es el abstracto de vernehmen, captar; así, esa frase se entendería mejor diciendo que hay un pronunciamiento sobre la legitimidad de esa captación, de manera que la "Vernunft" es la captación implicada su legitimidad.

La fenomenología quiere analizar qué significa ese pronunciamiento de legitimidad de la razón, o de la captación racional. Su respuesta es que la conciencia racional, es decir, la vivencia de la legitimidad de una captación tiene como modelo toda donación originaria, cada una en su esfera, pero en el $\S 139$ se ponen las bases de la descripción de la racionalidad básica originaria que pertenece a la creencia originaria, a la Urdoxa, o Urglaube, que es el carácter inherente a la percepción; ahí hay un "Urvernunftcharakter", un "carácter de una razón originaria", hasta el cual lleva toda pretensión de legitimidad racional en otros terrenos. Por eso todas las líneas de legitimidad llevan a la "creencia originaria", "Urglaube" y a su "razón originaria", "Urvernunft", o respectivamente, a la "verdad originaria, la verdad en sentido absoluto", "Urwahrheit, der Wahrheit im absoluten Sinn", aunque hay que decir, que lo del sentido absoluto es un añadido posterior, que, por otro lado, no afecta al sentido, sino que lo aclara.

Es posible que se diga que todo esto está entre paréntesis; ese dato, sin embargo, no afecta a lo fundamental, porque lo que se está describiendo es el modo de ser la conciencia trascendental que tiene conciencia del mundo y las cosas en él. Lo que ocurre es que en este momento Husserl aún no tiene absolutamente elaborada la diferencia entre la conciencia trascendental directa que está describiendo, y la conciencia fenomenológicamente que práctica la reducción y la epojé y por tanto no está comprometida con los resultados de la conciencia trascendental.

\section{La teoría de Lester Embree}

El libro de Lester Embree sobre el método fenomenológico representa una aportación de gran calado para el movimiento fenomenológico. En él podrá encontrar el lector una clara guía para moverse por las grandes rutas, por los caminos y senderos de los problemas de la fenomenología. La claridad, sus méritos didácticos y su traducción casi simultánea a varios idiomas le augura 
una gran influencia al menos en el ámbito de la fenomenología viva. Dicho esto, una de las mejores pruebas de estima del libro es dialogar con él. Las líneas que siguen son resultado de esa actitud. Para mi exposición voy a tomar el resumen que dedico en mi presentación del libro, ${ }^{4}$ que me parece adecuado para lo que quiero hacer. Los capítulos IV y V, en los que quiere aportar una análisis sistemático de la vida intentiva, se corresponderían un tanto con la sección III de las Ideas I; en ellos se trata de ofrecer "algunas doctrinas principales" (p. 259), o sea, conjuntos de pensamiento relativamente sistemáticos. El capítulo IV está dedicado a los tres modos fundamentales de la experiencia concreta, el V, a un modo abstracto, que siempre se da en los modos anteriores. El tema fundamental es la diferencia que se daría entre la experiencia concreta, que sería el modo posicional (creer, valorar y querer o hacer, sean todos o cada uno de ellos, en la modalidad de la "seriedad" o en la "ficción"), y la experiencia que les subyace, sea directa o indirecta; el tema queda ilustrado en el cuadro 4.1 (p. 257); este cuadro tendría una función doble, por un lado establece los dos puntos de que se tratará en cada uno de los capítulos que siguen, la posicionalidad (cap. IV) y la experiencia (cap. V). Ahora bien, esa diferencia se establece como dos especies de la intencionalidad que estarían en el mismo rango. Esto se deduce de cuando se habla de la "distinción más amplia" (p. 259), que sería la indicada, aunque, por otro lado, esa diferencia sea resultado de una "discriminación abstracta".

Por ejemplo, ante una puerta tendríamos dos posibilidades, o bien, nos fijamos en la experiencia de la puerta (percibida, recordada o esperada (p. 261), o nos fijamos en el modo como nos dirigimos a esa puerta y la consideramos en las modalidades concretas en que se da, creyéndola como existente, valorándola como elegante o bien ajustada a su marco, o actuando con ella, abriéndola para entrar en la habitación; en este caso nos centramos en su posicionalidad. Tenemos, por tanto, una diferencia entre la experiencia "percepción", y la experiencia posicional "creencia". Por tanto, podemos dejar de lado (be set aside, 338; cfr. también p. 318) todos los componentes posicionales, para centrarnos en los elementos experienciales, y entonces nos aparecen los diversos rasgos, bien de experiencia directa, en el presente, en el pasado, bien de experiencia indirecta, pictórica, indicativa o lingüística.

La presentación que hace L.E. es didácticamente muy clara, además, empezar por las modalidades de la posicionalidad ofrece de entrada un análisis más cercano y eficaz de la experiencia de lo que hace Husserl, que generalmente empieza por la experiencia. L.E. comienza por el análisis de la experiencia tal como es, con lo que quedan desactivadas las acusaciones que se hacen al método fenomenológico de fijarse sólo en aspectos teóricos. Aún hay otra considerable ventaja en la presentación de L.E., a saber, comenzar por el 
análisis de la capa afectiva valorativa; de ese modo rompe también una tradición que seguramente es perversa y que, además, contribuye a alejar la filosofía de los ciudadanos. Con ello supera realmente los vicios modernos, ya que por desconfiar los filósofos modernos frente a los resultados del conocimiento, tenían que empezar asegurándolo. Con ello se olvidaban del mundo afectivo, decisivo para lả comprensión efectiva de la vida y mundo humanos. L.E. empieza directamente analizando la posicionalidad valorativa, la menos atendida en la filosofia.

Además, es notable el partido que le saca a ese comienzo, estableciendo una diferencia fundamental entre dos modos de esa posición - y esto le va a servir como modelo general para toda forma que tenemos de estar en el mundo -, la diferencia entre fondo y forma o fondo y foco. En el amplio mundo de los sentimientos, en el que se asienta la valoración, los estados de ánimo hacen de fondo, los sentimientos de foco. Por aquél tenemos una valoración general de las cosas, por éstos estimamos, positiva o negativamente, personas, situaciones concretas o cosas. Y lo más interesante es que esa dualidad se aplica a las otras dos modalidades de la posicionalidad, la de la creencia, dando así un sentido muy claro a lo que en la fenomenología se llama "actitud", por ejemplo, la llamada actitud natural, que sería el modo de la experiencia de poner el mundo como realidad existente general, y los modos concretos por los cuales tomamos partido o ponemos cosas concretas existentes, de las cuales, por otro lado, podemos dudar, o que pueden mostrarse como distintas, pero siempre sobre el fondo de aquella actitud general. Y lo mismo vale para el tercer modo posicional, la acción, palabra preferida por L.E. para designar el campo de la voluntad, porque la voluntad efectiva es la acción, a diferencia por ejemplo del deseo, que es un intermedio entre el valorar y el querer activo. En correspondencia con lo anterior, también aquí existe un querer global y un querer focal (p. 305).

Con esto podemos pasar, progresando de lo más concreto a lo más abstracto, a la presentación, en el cap. V, de la experiencia que siempre subyace a los modos posicionales. Los desarrollos son muy interesantes, presentados de un modo, desde una perspectiva didáctica, muy útil y, "doctrinariamente", bien elaborado. Aquí se clasifican los dos tipos esenciales, la experiencia directa (con sus cuatro clases - la percepción, el recuerdo y la expectativa (tres especies, p. 361) y la experiencia de objetos ideales (p. 391) - y la experiencia indirecta en sus tres modalidades, la pictórica (no restringida el género "pintura", sino a toda experiencia por representación semejante), la indicativa y la lingüística. En cuanto al modo como se llega al nivel de la experiencia, vuelve a aparecer el proceso abstractivo: eliminando los elementos posicionales, entonces nos quedamos en algo semejante a lo que se enfoca en la experiencia naturalista (p. 339); un poco más adelante se dice que los objetos logrados por esa abstracción en realidad son objetos naturalistas, y así queda eso señalado 
con claridad, cuando se habla de objetos ideales, pues, dejando de lado los objetos ideales, se "trata [...] de un interés en los objetos naturalistas" (p. 347).

Al final del capítulo se aborda la experiencia lingüística como una de las experiencias indirectas más importantes; en ella, el infraestrato lingüístico -lo sensorialmente percibido, recordado o esperado, por tanto en experiencia directa- suscita, "en virtud del aprendizaje" (p. 377), un concepto o significación cuyo carácter ontológico es ser "un objeto ideal". El capítulo concluye con el rechazo del "lingualismo", según el cual "toda representación involucra significaciones" (p. 389), que suele llevar a pensar en que "todas las representaciones son expresiones" (ib.), ignorando que el mundo real se nos da en una experiencia directa mediante los sentidos.

Aunque en conversaciones privadas en las que hemos intercambiado opiniones Lester Embree me ha sugerido que parece que decimos lo mismo, yo creo que entre la propuesta husserliana y la suya hay una diferencia importante, porque la percepción aparece en Lester Embree como un modo de la experiencia, antes de cualquier posicionalidad, mientras que en Husserl la percepción es un acto ponente que incorpora la creencia. Para Husserl la percepción, que es el modelo de racionalidad, en la que se enraíza la "razón originaria", la Urvernunft, lleva consigo la creencia, la creencia no es una posicionalidad añadida a la percepción, porque no hay percepción sin posicionalidad, porque la percepción implica la certeza de la existencia del mundo, como primera apertura al mismo. Más aún, yo creo que la percepción es justo nuestro anclaje en el mundo, que ocurre como creencia originaria, Urdoxa o Urglaube, modelo de toda otra creencia, de manera que entonces cobra pleno sentido la frase que Ortega y Gasset toma del escritor español Pío Baroja y que el filósofo madrileño convertirá en cierta manera en uno de los ejes de su filosofía, de que "en todo lo que se cree se cree igual". El acierto de esa frase no está en que la creencia es una posicionalidad que le adviene a una experiencia que ya es por sí perceptiva, como puede ser rememorativa, y en ese sentido puede advenirle después una de las características posicionales, la creencial, valorativa o activa. Yo creo más bien que tenemos un modelo originario de creencia, la Urdoxa, que es la forma fundamental y primera de toda conciencia, de lo que Husserl llama Erfahrungsbewusstsein, conciencia de experiencia, cuyo correlato es el mundo real, y sobre la cual se miden todas las demás como diversas modificaciones de la misma. Y eso es ni más ni menos el rendimiento de la percepción. 


\section{La percepción como interpretación}

No voy a dedicar un espacio excesivo a este punto, sino sólo delinear un tema que, por otro lado, he tratado en otro lugar, ${ }^{5}$ pero que, me parece consustancial al enfoque husserliano por más que quede en él un poco oscurecido $\mathrm{y}$, en mi opinión, no resuelto en la aproximación de Lester Embree. El oscurecimiento viene de que expresamente parecen quedar eliminados los predicados provenientes de la cultura, de manera que los ejemplos que pone Husserl nos hacen confrontarnos en el caso de la percepción con cosas naturales, en las que parece que el lenguaje y la cultura no han depositado su carga significativa. Husserl lamenta este olvido en el último texto suyo publicado en Hua XXIX.

En la teoría de L. Embree hay un rechazo explícito a la productividad perceptiva de la interpretación. Distingue en efecto un lingualismo moderado de uno exagerado, distinguiendo, con gran acierto, el estar "infectada" la percepción por el lenguaje, del estar "afectada" por él. Por razones de tiempo no puedo dedicar aquí más tiempo al asunto. Sólo quiero indicar que en la teoría husserliana la expresión es una capa posterior de la conciencia de experiencia, por tanto de la percepción. Esto no obstante, hay que tener en cuenta la existencia en la percepción de un contenido descriptible en predicados conceptuales, es decir, que habría una correspondencia entre el contenido de la percepción y su descripción lingüística. Esa correspondencia nos lleva a preguntarnos si lo que percibimos no ha estado realmente organizado por el lenguaje, inicialmente en la forma más material perceptual del mismo, es decir, como sonido, y justamente en ese sentido, dado que los sonidos conectados con las propiedades sensibles dependientes de las cinestesias sensibles, están en una relación cultural personal, de siempre, de siempre la percepción humana, está imbricada con el lenguaje, la cultura, los usos culturales. Dicho de otro modo, la percepción ha sido cultivada por el lenguaje desde el principio. La cultura no abarca sólo los elementos de valoración o acción, sino también los elementos de percepción. Por eso la percepción es experiencia e interpretación. La interpretación procede de la conexión que un "qué con su contenido noemático" determinado experimenta al ser enmarcado en un uso o, y es lo normal, en una denominación del uso, denominación tan material como la propia experiencia, aunque sea perteneciente a otro orden. Desde el momento en que un "nóema" queda vinculado a una denominación, la percepción es ya interpretación, porque en el contenido del nóema se incorpora la denominación o descripción de algo que en sentido estricto no depende de la experiencia directa de ese elemento percibido, por ejemplo, una denominación lingüística o un uso. El uso potencialmente vinculado a una cosa no es realmente uso de esa cosa, sino modo de percibir esa cosa. Esa percepción no es el uso, sino anterior al uso. Por eso la percepción incluye una interpretación. Y por eso describir

5 Ver Javier San Martín, Teoría de la cultura, Editorial Síntesis, Madrid, 1999, sobre todo capítulo 2, "Fenomenología de la cultura", pp. 127 ss. 
una percepción es mucho más que describir la presencia sensible dependiente del campo sensible afectado. De ahí que los análisis de la percepción que suele realizar Husserl dan siempre la impresión de desenvolverse en un campo naturalista, sin cultura. Cuando hace él la crítica al olvido del mundo histórico concreto, no rechaza los análisis previos de la percepción. En realidad la ampliación de sus análisis de la percepción a una percepción que integra lo cultural no exige ningún cambio, "sino sólo tomar conciencia de que las determinaciones culturales referidas a la valoración y acción de una cosa quedan incorporadas al sentido noemático de la percepción, que además es perfectamente descriptible en predicados conceptuales.

Tal vez todo esto es lo que estaba implícito en los análisis de la percepción que llevó a cabo Schapp, en su tesis doctoral, tomados, en gran medida, de las lecciones de Husserl, principalmente de 1907, y según los cuales la percepción cuenta con ideas que animan los datos sensibles. Esas ideas son obviamente el contenido noemático, y en éste se incluyen todos los predicados culturales que definen las cosas en el contexto de significatividad cultural que tan brillantemente describió Heidegger. Pero con ello no estaba superando a Husserl, solamente explicitaba algo que es perfectamente encajable en las Ideas I de Husserl.

\section{ABSTRACT}

Mi ponencia trata de contribuir a una fenomenología de la percepción, desde la discusión de las posturas sobre la percepción que aparecen en la reciente obra de Lester Embree sobre el método fenomenológico. Desde el convencimiento y asentimiento a la llamada de Lester Embree, de que debemos volver a las cosas mismas, por tanto, dejarnos de la erudición para alumbrar fenomenología de las cosas, no podemos tampoco desentendernos de lo que dicen nuestros maestros, y pretendo, con ellos, ir a las cosas, para ver en qué medida la percepción como acceso al mundo es un "acto" en el que intervienen la experiencia directa sensible animal y la aportación lingüística que clasifica el mundo, sin por ello convertir la percepción en lenguaje. En el primer punto plantearé la importancia que el tema tiene en la fenomenología sobre todo por el planteamiento husserliano en las Ideas I. En el segundo veremos la postura de Lester Embree, para, en el tercero, exponer lo que yo creo que está implícito en la propuesta de Husserl, que explicita la percepción como el acceso ponente a la realidad, por tanto radicalmente vinculada a la creencia, de manera que, fenomenológicamente, percepción, creencia y realidad están vinculadas, siendo está vinculación el marco en el que sitúa el comienzo de la legitimidad racional. 
